\title{
Mısır Varyetelerinde Yabancı Ot Kontrolü için Kritik Periyotların Belirlenmesi
}

\author{
${ }^{*}$ Nihat TURSUN ${ }^{1}$ Mahmut Sami SAKINMAZ ${ }^{2}$ Zekeriya KANTARCI ${ }^{3}$ \\ ${ }^{1}$ İönü Üniversitesi, Ziraat Fakültesi, Bitki Koruma Bölümü, Battalgazi, Malatya \\ ${ }^{2}$ Kahramanmaraş Sütçü İmam Üniversitesi, Fen Bilimleri Enstitüsü, Kahramanmaraş \\ ${ }^{3}$ Doğu Akdeniz Geçit Kuşağı Tarımsal Araştırma İstasyonu, Kahramanmaraş \\ *Sorumlu yazar e-posta (Corresponding author; e-mail): nihat.tursun@inonu.edu.tr
}

\section{Öz}

Bu çalışma üç mısır varyetesinde (patlak mısır, at dişi mısır ve şeker mısır) 2013-2014 yıllarında Kahramanmaraş Doğu Akdeniz Geçit Kuşağı Tarımsal Araştırma İstasyonu'nda yabancı ot kontrolü için kritik periyodun belirlenmesi amacıyla yapılmıştır. Çalışma sonucunda dört parametreli log-logistik model yardımıyla yabancı otlu ve yabancı otsuz sürenin oransal mısır verimine olan etkisi hesaplanmıştır. Mısır varyetelerinin oransal verimi yabancı otlu veya yabancı otsuz periyottan etkilenmiştir. Yabancı otlu süre arttıkça her iki yılda da mısır verimleri önemli oranda azalmıştır. Patlak mısırda yabancı otsuz kalması gereken süre kabul edilebilir \%10 verim kaybında 2013 yılında 145-530 GDD (V1-V8 yapraklı dönem) olurken, 2014 yılında156-550 GDD (V1-V8 yapraklı dönem) olarak hesaplanmıştır. At dişi mısırda 2013 yılında 228-640 GDD (V2-V10 yapraklı dönem) belirlenirken, 2014'de ise 200-521 GDD (V2-V8 yapraklı dönem) saptanmıştır. Şeker mısırda ise bu süreler 2013 yılında 258-520 GDD (V3-V8 yapraklı dönem) ve 2014 yılında ise 217-512 GDD (V2-V8 yapraklı dönem) olduğu belirlenmiştir. $\mathrm{Bu}$ çalışma sonucunda \%10 verim kaybı göz önünde bulundurulduğunda mısır varyetelerine bakılmaksızın mısırın V2 yapraklı dönemden itibaren başlamak üzere V10 yapraklı döneme kadar yabancı otlarla mücadele edilmesi gerektiği sonucu ortaya çıkmaktadır.

Anahtar Kelimeler: Mısır varyeteleri, yabancı otlu ve otsuz periyot, yabancı ot alım zamanları rekabet

\section{Corn Varieties Influenced the Critical Period for Weed control in Corn}

\begin{abstract}
Field experiments were conducted in 2013 and 2014 in the Agricultural Research Institute, Kahramanmaras, Turkey to determine the effects of three corn varieties (pop corn, dent corn and sweet corn) on the critical period for weed control (CPWC) in corn. A four parameter log-logistic model was fit to data relating relative crop yield to both increasing duration of weed interference and length of weed-free period. The relative yield of corn was affected by the duration of weed-infested or weed-free period, regardless of the corn varieties. Increasing periods of weed interference significantly reduced corn yields in both years. In the pop corn, the CPWC ranged from 145-530 GDD (V1-V8 growth stages) in 2013 and 156-550 GDD (V1V8 growth stages) in 2014 based on the $10 \%$ acceptable yield loss (AYL) level. In the dent corn, the CPWC ranged from 228-640 GDD in 2013 (V2-V10 growth stages) and 200-521 GDD (V2-V8 growth stages) in 2014. Also in the sweet corn, the CPWC ranged from 258-520 GDD in 2013 (V3-V8 growth stages) and 217-512 GDD (V2-V8 growth stages) in 2014. The main practical implication of this study is that the weed management should be initiated around V2 stage of corn and maintained weed free up to V10 stage in order to prevent yield losses.
\end{abstract}

Keywords: Corn varieties, period of weeded and critical weed-free period, timing of weed removal, competition

\section{Giriş}

abancı otlar dünya genelinde yabancı ot kontrolü yapılmadığında ortalama $\% 29.2$ ve yabancı ot mücadelesi yapıldığında bile \%12.8 verim kayıpları ortaya çıkarmasından dolayı mısırda ürün kayıplarına yol açan en önemli faktörlerden birisidir (Oerke ve Steiner, 1996). Bu yüzden yabancı ot kontrolü mısır üretiminde optimum ürün elde edilebilesi açısından önemli bir faktördür. Ürün kayıpları yabancı ot türleri, yabancı ot yoğunluğu, 
yabancı ot dağııımı, toprak yapısı, toprak nemi ve topraktaki organik madde miktarı gibi birçok faktöre bağlıdır. Mısırda yabancı ot kontrolü hem mekaniksel hemde kimyasal olarak yapılmaktadır. Mısırda sıra üzerindeki yabancı otlar el veya hebisitle alınırken, sıra arasındakiler ise genellikle mekanik yöntemlerle ortadan kaldırılmaktadır. Her iki yöntemde yabancı ot kontrolünde etkili olmasına rağmen, üretim masraflarını arttırmaktadır (Doğan ve ark. 2004). Mısır Türkiye'de önemli tarla bitkilerinden biridir. 2013 yılında 660.000 ha alandan 5.9 milyon ton mısır ürünü elde edilmiştir (Anonim, 2014).

Yabancı ot ve ürün arasında intersipesifik rekabetin olduğu ürün gelişimi esnasındaki zaman dilimi olarak tanımlanan kritik periyot kavramı tarımda ilk defa 1960'ı yılların sonuna doğru geliştirilmiştir (Zimdahl 1988). Bir kültür bitkisinin gelişme dönemi içerisinde, yabancı ot mücadelesi sonucu verim artısının maksimuma yaklaştığı nokta ile yabancı ot mücadelesi yapılmaması halinde verim kaybının aniden başladığı nokta arasındaki süreye "Kritik Periyot" denir (Bükün ve Uygur 1997; Işık ve ark. 2006; Güncan, 2009). Tarım alanlarında yoğun oldukları belirlenen yabancı otların üründe verim ve kalite yönünden meydana getireceği zararın tespit edilmesi, bu alanda yabancı otlarla kültür bitkisi arasındaki rekabetin incelenerek bu rekabetin kültür bitkisi ve yabancı otun hangi dönemlerinde önemli olduğunun belirlenmesi kritik periyodun amacını oluşturmaktadır.

Ülkemizde kültür bitkilerimizin yetiştirilmesinde yabancı otlar oldukça önemli bir problem oluşturmaktadır. Yabancı otlarla mısırın mısır çıkışından itibaren ilk 2-8 yapraklı periyotta olmaktadır (Özer ve ark. 2001).

Mısır yetiştiriciliğinde yabancı otlarla kritik periyodu belirlemeye yönelik bazı çalışmalar bulunmasına rağmen, mısır variyetelerinde yabancı otlar için kritik periyodun etkilerine yönelik bir çalışma yoktur. Bu nedenle, üç farklı mısır varyetesinde (at dişi, şeker ve cin mısır) yabancı otlarda kritik periyodun belirlenmesi amacıyla bu çalışma yapıımıştır.

\section{Materyal ve Yöntem}

Çalışmanın ana materyalini üç farlı mısır varyetesi (at dişi, şeker ve cin) ve msır tarlasında sorun oluşturan yabancı otlar oluşturmuştur. Akdeniz Bölgesinde yer alan Kahramanmaraş ili, kuzeyinde; Sivas, Malatya, Kayseri; güneyinde Gaziantep; doğusunda Adıyaman; batısında Adana ve Osmaniye illeri ile sınırlıdır. $37^{\circ}-36^{\prime}$ kuzey enleminde $36^{\circ}-55^{\prime}$ doğu boylamında yer almaktadır. Yüzölçümü 14.328 km$^{2}$ 'dir. En önemli ovaları Narlı, Göksun ve Elbistan'dır. Yabancı ot rekabetinin mısır varyetelerinin verimine olan etkisi ve kritik periyodun belirlenmesi amacıyla tarla denemesi, 2013 - 2014 yıllarında Kahramanmaraş Doğu Akdeniz Geçit Bölgesi Tarımsal Araştırma Enstitüsü arazisinde kurulmuştur.

Deneme alanı, sırasıyla $25-30 \mathrm{~cm}$ derinlikte pullukla sürme, kazayağı ile işlenme, diskaro ile toprak karıştırma ve tapanla düzeltme yapılarak ekime hazır hale getirilmiştir. Mısır tohumları araziye ekiminde cin mısırı 12 Nisan 2013 ve 21 Nisan 2014, at dişi ve şeker mısır ise 12 Nisan 2013 ve 7 Nisan 2014 tarihlerinde $70 \mathrm{~cm}$ sıra arası ve $35 \mathrm{~cm}$ sıra üzeri mesafe olacak şekilde ekilmiştir. Denemeler, Tesadüf Bloklarında Bölünmüş Parseller deneme desenine göre 3 tekerrürlü, toplam 9 blok ve her blokta 10 parsel olacak şekilde kurulmuştur. Denemede mısır varyeteleri (at dişi, şeker ve cin mısır) ana parselleri, yabancı ot alım zamanları ise alt parselleri oluşturmuştur. Ekimle beraber dekara saf olarak $9 \mathrm{~kg} / \mathrm{da}$ Azot, $9 \mathrm{~kg} / \mathrm{da} \mathrm{P}_{2} \mathrm{O}_{5}$ ve $9 \mathrm{~kg} / \mathrm{da} \mathrm{K}_{2} \mathrm{O}$ olacak şekilde gübre dozları uygulanmıştır. Mısır bitkisi 30-40 $\mathrm{cm}$ boya ulaştığında $30 \mathrm{~kg} / \mathrm{da}$ azot uygulaması üre formunda tarlaya verilmiştir.

Mısır varyeteleri ana parseller, yabancı ot alım zamanları ise alt parselleri oluşturmuştur. Aşağıda ot alım zamanları verilmiştir.

Mısır çıkışından itibaren devamlı yabancı otsuz tutma (kontrol-1).

Mısır çıkışından itibaren 10 gün sonra yabancı ot alımı ve 10. günden itibaren devamlı yabancı otsuz tutma.

Mısır çıkışından 20 gün sonra yabancı ot alımı ve 20. günden itibaren devamlı yabancı otsuz tutma.

Mısır çıkışından 30 gün sonra yabancı ot alımı ve 30. günden itibaren devamlı yabancı otsuz tutma.

Mısır çıkışından 40 gün sonra yabancı ot alımı ve 40. günden itibaren devamlı yabancı otsuz tutma.

Mısır çıkışından itibaren devamlı yabancı otlu tutma (kontrol-2).

Mısır çıkışından 10 gün yabancı ot alımı ve 10. günden itibaren devamlı yabancı otlu tutma.

Mısır çıkışından 20 gün yabancı ot alımı ve 20. günden itibaren devamlı yabancı otlu tutma. 
Mısır çıkışından 30 gün yabancı ot alımı ve 30. günden itibaren devamlı yabancı otlu tutma.

Mısır çıkışından 40 gün sonra yabancı ot alımı ve 40. günden itibaren devamlı yabancı otlu tutma.

Hektara çevrilmiş verim verileri ve diğer veriler ANOVA testine tabi tutulmuştur. Parsellerden elde edilen kütlü verimler, sezon boyu yabancı otsuz parselden elde edilen kütlü verime oranlanarak nisbî verim hesaplanmıştır. Çalışmalarda kullanılan Günlük Gelişme Derecesi (GGD) McMaster ve Wilhelm (1997) ve Yang ve ark. (2004)'e göre hesaplanmıştır. Burada temel sıcaklık $10^{\circ} \mathrm{C}$ olarak kabul edilmiştir. Bir günün en yüksek sıcaklık değeri (Tmax) $30^{\circ} \mathrm{C}$, en düşük sıcaklık değeri (Tmin) $10^{\circ} \mathrm{C}$ alınmıştır. Tmax için $30^{\circ} \mathrm{C}$ 'den yüksek sıcaklıklar $30^{\circ} \mathrm{C}$ ve Tmin için ise $10^{\circ} \mathrm{C}$ 'nin altındaki sıcaklıklar $10^{\circ} \mathrm{C}$ olarak alınmıştır. GGD için denemeye Data Logger yerleştirilmiş ve toprağın $5 \mathrm{~cm}$ altındaki sıcaklıklar günlük olarak data loggerda toplanmıştır. Daha sonra veriler bilgisayara aktarılarak GGD hesaplamaları yapılmıştır. Böylece yabancı ot alım zamanları GGD hesaplamaları üzerinden belirlenmiştir.

$G G D=\left[\left(T_{\max }+T_{\min }\right) / 2\right]-T_{b}$

$G G D=$ Günlük Gelişme Derecesi

$T_{\text {max }}$ : bir günün en yüksek sıcaklık değeri $\left({ }^{\circ} \mathrm{C}\right)$,

$\mathrm{T}_{\min }$ : bir günün en düşük sıcaklık değeri $\left({ }^{\circ} \mathrm{C}\right)$,

$\mathrm{T}_{\mathrm{b}}$ : baz sıcaklık

Yabancı otlarla mücadelede kritik periyodu (YOMKP) hesaplamak için, oransal veriler PROC NLMIXED prosedürüne bağlı olarak regresyon analizine tabi tutulmuştur. İstatiksel analizler, Knezeviç et al. (2007) tarafından önerilen modellere göre yapılmıştır. Ürün kayıpları (\%) ve yabancı ot kuru ağırlıkları dört parametreli log-logistik model kullanılarak yapılmıştır (Knezevic et al. 2007). Bu model kullanılan formül aşağıda verilmiştir.

$$
Y=\frac{C+(D-C)}{(1-\exp [\mathrm{B}(\log X=\log E])}
$$

Bu denklememde; $Y=$ oransal verim, $C=$ alt limit, $D=$ =uss limit, $X=$ bitki çıkışını takip eden

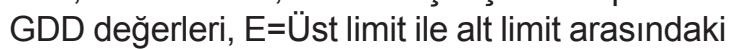
\%50 tepkime, $\quad \mathrm{B}=$ Değişim aralığını göstermektedir.

Bütün istatistiki analizler ve grafikler doztepki (drc) eğrileri istatistik paket program yardımı ile $\mathrm{R}$ program (R Development Core
Team, 2006) ile yapılmıştır. Bu programa göre \%2.5 (YR 2.5$)$ \%5 $\left(\mathrm{YR}_{5}\right)$ ve \%19 $\left(\mathrm{YR}_{10}\right)$ verim kayıpları GDD değerleri üzerinden hesaplanmıştır.

\section{Bulgular ve Tartışma}

Deneme arazisinde dominanat yabancı otlar olarak Amaranthus retroflexus, Anagallis arvensis, Chenopodium album, Convolvulus arvensis, Cyperus rotundus, Datura stramonium, Portulaca oleracea, Solanum nigrum, Sorghum halepense, Tribulus terrestris ve Xanthium strumarium saptanmıştır. Bu yabancı otların hepsi bölgedeki diğer yazlık kültür bitkilerinde de saptanmıştır (Kadioglu ve ark. 2004; Gözcü ve Uludağ, 2005; Tursun ve ark. 2012). Hasattan önce kontrol parsellerinde yapılan sayımlar sonucunda şeker mısırında 2013 yılında 35, 2014 de 40, at dişi mısırda 2013 de 40 ve 2014 yılında 37 ve şeker mısır da ise 2013 yılında 34 ve 2014 de ise 37 bitki $/ \mathrm{m}^{2}$ olarak yabancı otlar tespit edilmiştir. Yabancı ot yoğunlukları her üç mısır varyetesinde de benzer çıkmıştır.

Yabancı otlarla kritik period boyunca uygulamalara ve yıllar arasında interaksiyon bulunmuştur. Bu yüzden bütün veriler her bir yıl için ayrı ayrı analiz edilmiştir (Şekil 1, Çizelge 1). Her iki yılda da yabancı otlu periyot arttıkça mısır varyetelerindeki verimde önemli azalışlar meydana gelmiştir.

Mısırda varyeteler arasında yabancı otlarla mücadelede kabul edilebilir ürün kaybı \%10'dan \%2.5'e gidildikçe üründe azalma olduğu saptanmıştır. \%10 kabul edilebilir ürün kaybında cin mısırda yabancı otlar için kritik periyodun başlangıcı 2013 yılında 145, 2014 yılında ise 156 GGD olarak hesaplanmıştır. Bu da cin mısııın çıkışından sonraki 16-19. gün olarak hesaplanmıştır. At dişi mısırda ise bu durum 2013 yılında 228, 2014 yılında ise 200 GGD olarak saptanmıştır. $\mathrm{Bu}$ ise at dişi mısırın çıkıştan sonraki 24. gününe denk gelmektedir. Şeker mısırda ise 2013 yılında 258 ve 2014 yilında ise 217 GGD olarak bulunmuştur. Buda şeker mısırın çıkışından sonraki 26-27. gün olarak saptanmıştır (Çizelge 2). Yabancı otlarla mücadelede kritik periyodun bitiş zamanında ise yıllar arasında değişiklikler saptanmıştır (Şekil 1). Yüzde 10 kabul edilebilir ürün kaybında cin mısırda yabancı otlar için kritik periyodun bitişi 2013 yılında 530, 2014 yılında ise 550 GGD olarak hesaplanmıştır. Bu da cin mısırın çıkışından sonraki 50-49. gün olarak hesaplanmıştır. At dişi mısırda ise bu durum 
Çizelge 1. Mısııın oransal veriminde yabancı otlu ve yabancı otsuz dönem için uygulanan dört parametreli log-logistik model için sıra arası mesafe ve yıllara için belirlenmiş parametreler ( \pm SE).

Table 1. Regression parameters for row spacing and years on four parameter log - logistic model (for relating relative crop yiled to both increasing duration of weed interference and length of weed-free period)

\begin{tabular}{cclcccc}
\hline Mısır & Yıl & Uygulamalar & \multicolumn{4}{c}{ Regrasyon parametreleri $( \pm$ SE) } \\
\cline { 4 - 7 } varyeteleri & & & $\mathrm{B}$ & $\mathrm{C}$ & $\mathrm{D}$ & $\mathrm{I}_{50}$ \\
\hline Cin mısır & 2013 & Yabancı otlu & $1.7(0.3)$ & $22.4(6.0)$ & $100.2(2.2)$ & $542.9(67.5)$ \\
& 2013 & Yabancı otsuz & $-5.1(1.0)$ & $34.4(2.3)$ & $95.7(2.9)$ & $343.3(12.2)$ \\
& 2014 & Yabancı otlu & $2.2(0.3)$ & $27.2(3.5)$ & $101.2(2.6)$ & $428.7(31.5)$ \\
& 2014 & Yabancı otsuz & $-3.6(1.5)$ & $18.5(16.4)$ & $94.3(6.2)$ & $297.3(31.3)$ \\
At dişi mısır & 2013 & Yabancı otlu & $2.8(0.5)$ & $19.5(3.0)$ & $96.6(2.3)$ & $501.1(25.8)$ \\
& 2013 & Yabancı otsuz & $-3.6(1.2)$ & $32.9(3.8)$ & $94.4(5.8)$ & $346.3(21.8)$ \\
& 2014 & Yabancı otlu & $3.9(0.7)$ & $20.8(2.9)$ & $95.5(2.6)$ & $351.3(15.9)$ \\
& 2014 & Yabancı otsuz & $-3.3(1.5)$ & $29.9(8.6)$ & $104.8(12.9)$ & $265.3(23.4)$ \\
Şeker mısır & 2013 & Yabancı otlu & $3.1(0.5)$ & $21.8(2.8)$ & $97.7(2.1)$ & $518.2(24.6)$ \\
& 2013 & Yabancı otsuz & $-4.7(1.1)$ & $31.1(2.7)$ & $98.5(3.4)$ & $324.6(12.1)$ \\
& 2014 & Yabancı otlu & $4.3(0.8)$ & $21.5(3.0)$ & $96.8(2.5)$ & $362.3(15.3)$ \\
& 2014 & Yabancı otsuz & $-3.5(1.1)$ & $25.8(5.5)$ & $106(9.9)$ & $274.8(18.5)$ \\
\hline
\end{tabular}

B: Değişim aralığı; C: alt limit; D: üst limit; $I_{50}$ : alt ve üst limit arasında $\% 50$ tepkime için verilen GGD değerleri. B: Range, C: Lower Limit, D: upper limit, $I_{50}$ : GDD (Growing Degree Days) values producing a response half way between lower limit and upper limit.
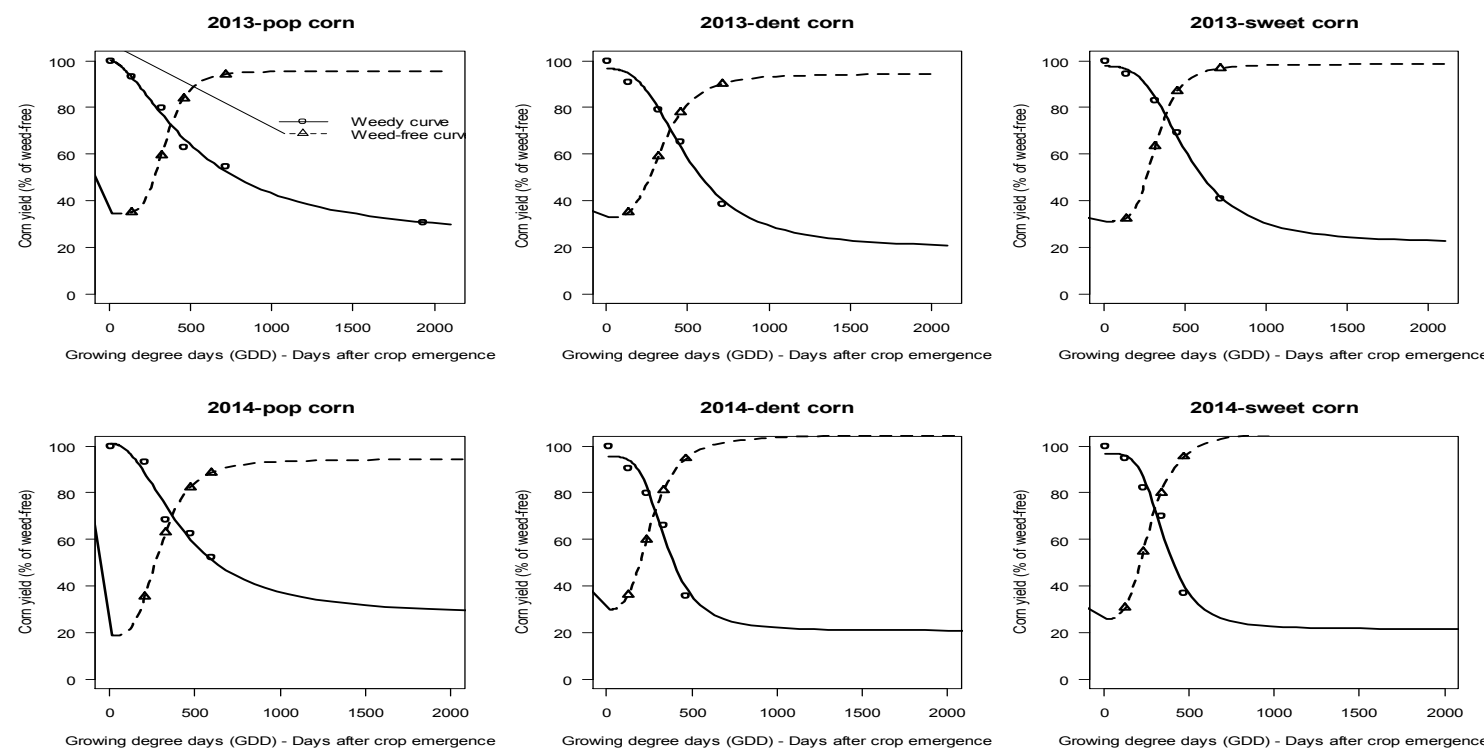

Şekil 1. 2013 ve 2014 yıllarında GGD değerleri üzerinden verilen üç mısır varyetesinde (cin mısır, at dişi mısır ve şeker mısır) yabancı otların etkileri.

Figure 1. Effects of weeds on three corn varieties (pop corn, dent corn and sweet corn) on their GDD (Growing Degree Days) in 2013 and 2014

2013 yılında 640, 2014 yılında ise 521 GGD olarak saptanmıştır. $\mathrm{Bu}$ ise at dişi mısırın çıkıştan sonraki 59-52. gününe denk gelmektedir. Şeker mısırda ise 2013 yılında 520 ve 2014 yılında 512 GGD olarak hesaplanmıştır. Bu ise şeker mısırın çıkışından sonraki 49-53. gün olarak saptanmıştır (Çizelge 2). Kritik periyodun kabul edilebilir ürün kaybı $\% 10$ 'dan \%2.5'e azaldıkça bir artış meydana gelmektedir.

Her iki yılda da mısır varyetelerindeki ürün kaybı yabancı otlu periyor arttıkça önemli ölçüde azalmaktadır. Bu sonuçlar Doğan ve ark. (2004) benzerlik göstermektedir. Bu çalışmada optimum düzeyde mısır ürünü almak için yaklaşık olarak mısırın VE (mısırın ilk çıkış dönemi) - V10 (mısırın 10 yapraklı olduğu dönem) dönemleri arasında yabancı otların kontrol altına alınması gerektiği sonucunu ortaya koymaktadır. Bu durum \%10 ürün kaybına göre cin mısırında $\mathrm{V} 1-\mathrm{V} 8$, at dişi mısırda V2-V10 ve şeker mısırda V2-V8 olduğu döneme denk gelmektedir. Bu sonuçlar Hall ve ark. (1992), Hurle ve ark. (1996) ve Doğan ve ark. (2004) ile benzerlik göstermektedir. 
Çizelge 2. 2013 -2014 yıllarında GGD olarak üç mısır varyetesinde (cin mısır, at dişi mısır ve şeker mısır) yabancı ot kontrolü için kritik periyot dönemleri.

Table 2. Critical periods for weed control of three corn varieties (pop corn, dent corn and sweet corn) on GDD in $2013-2014$

\begin{tabular}{|c|c|c|c|c|c|}
\hline \multirow[t]{2}{*}{ Yillar } & \multirow{2}{*}{$\begin{array}{c}\text { Ürün kaybı } \\
(\%)\end{array}$} & \multirow{2}{*}{$\begin{array}{c}\text { Mısır } \\
\text { varyeteleri }\end{array}$} & \multicolumn{3}{|c|}{ Kritik periyot için yabancı ot kontrolü (CPWC) } \\
\hline & & & GGD* & CGS $^{* *}$ & $\mathrm{DAE}^{* * *}$ \\
\hline \multicolumn{6}{|c|}{ Kritik periyodun başlangıcı } \\
\hline \multirow[t]{9}{*}{2013} & $2.5 \%$ & Cin misır & 60 & VE & 10 \\
\hline & & At dişi mısır & 135 & $\mathrm{~V} 1$ & 18 \\
\hline & & Şeker mısır & 162 & V1 & 20 \\
\hline & $5 \%$ & Cin misır & 92 & VE & 14 \\
\hline & & At dişi mısır & 175 & $\mathrm{~V} 2$ & 21 \\
\hline & & Şeker mısır & 203 & V2 & 23 \\
\hline & $10 \%$ & Cin misır & 145 & V1 & 19 \\
\hline & & At dişi mısır & 228 & V2 & 24 \\
\hline & & Şeker mısır & 258 & V3 & 26 \\
\hline \multirow[t]{9}{*}{2014} & $2.5 \%$ & Cin misır & 79 & VE & 8 \\
\hline & & At dişi mısır & 137 & V1 & 18 \\
\hline & & Şeker mısır & 154 & V1 & 19 \\
\hline & $5 \%$ & Cin misır & 110 & V1 & 12 \\
\hline & & At dişi mısır & 165 & V1 & 20 \\
\hline & & Şeker mısır & 182 & V2 & 22 \\
\hline & $10 \%$ & Cin misır & 156 & V1 & 16 \\
\hline & & At dişi mısır & 200 & V2 & 24 \\
\hline & & Şeker mısır & 217 & V2 & 27 \\
\hline \multicolumn{6}{|c|}{ Kritik periyodun bitişi } \\
\hline \multirow[t]{9}{*}{2013} & $2.5 \%$ & Cin misır & 709 & V11 & 63 \\
\hline & & At dişi mısır & 964 & V13 & 78 \\
\hline & & Şeker mısır & 713 & V11 & 64 \\
\hline & $5 \%$ & Cin mısır & 615 & V10 & 57 \\
\hline & & At dişi mısır & 788 & V12 & 68 \\
\hline & & Şeker mısır & 611 & V10 & 56 \\
\hline & $10 \%$ & Cin mısır & 530 & V8 & 50 \\
\hline & & At dişi mısır & 640 & V10 & 59 \\
\hline & & Şeker mısır & 520 & V8 & 49 \\
\hline \multirow[t]{9}{*}{2014} & $2.5 \%$ & Cin misır & 829 & V12 & 66 \\
\hline & & At dişi mısır & 817 & V12 & 73 \\
\hline & & Şeker mısır & 775 & V11 & 71 \\
\hline & $5 \%$ & Cin mısır & 678 & V10 & 57 \\
\hline & & At dişi mısır & 655 & V10 & 63 \\
\hline & & Şeker mısır & 632 & V10 & 61 \\
\hline & $10 \%$ & Cin mısır & 550 & V8 & 49 \\
\hline & & At dişi mısır & 521 & V8 & 52 \\
\hline & & Şeker mısır & 512 & V8 & 53 \\
\hline
\end{tabular}

*GGD : Gelişme gün derece, ** CGS : Mısırda yaprak durumu *** DAE : Çıkış sonrası gün

* GDD: Growing Degree Days, $\quad$ ** CGS: Leaf Stages, $\quad{ }^{* * *}$ DAE: Days after Emergence

\section{Sonuç}

Bu çalışmada \%10 verim kaybı göz önünde bulundurulduğunda mısır varyetelerine bakılmaksızın mısırda V2 yapraklı dönemden itibaren başlamak üzere V10 yapraklı döneme kadar yabancı otlarla mücadele edilmesi gerektiği sonucu ortaya çıkmaktadır. Bu sonuçlar yabancı otlarla mücadelede kritik periyodun yabancı ot yönetim stratejilerini geliştirmeye katkı sağlaması açısından önemli olduğunu göstermektedir.

\section{Kaynaklar}

Anonim, 2014. TUiK verileri, http://www.tuik.gov.tr

Bükün B, Uygur FN, 1997. Harran Ovası Pamuk Ekim Alanlarında Görülen Yabancı Otlarla En Uygun Mücadele Zamanının Saptanması Amacıyla Kritik Periyodun Belirlenmesi. Türkiye 2. Herboloji Kongresi Bildirilen, Ayvalık-izmir

Dogan M.N., Unay A., Boz O. and Albay F., 2004. Determination of optimum weed control timing in maize (Zea mays L.). Turk J Agric., 28: 349354 
Gözcü D. ve Uludağ A., 2005. Weeds in Cotton Fields and their Importance in Cotton in Kahramanmaraş, Turkey. Türk. Herb. Der., 8: $7-15$

Güncan A., 2009. Yabancı Otlar ve Mücadele Prensipleri, Selçuk Üniversitesi Basımevi.Konya

Hall M.R., Swanton C.J. and Anderson G.W., 1992. The critical period of weed control in grain corn. Weed Science, 40: 441-447.

Hurle K., Lechner M. and Knig K., 1996. Unkr.uter in Mais, In: Mais, Unkr.uter, Sch.dlinge, Krankheiten. Verlag TH. MANN. Gelsenkirchen, pp:16-17

Işık D., Mennan H., Bükün B., Oz A. and Nğouajio M., 2006. Türkiye'de mısır ot kontrolü için kritik dönem. yabancı ot teknolojisi. 20: 867872

Kadioglu I., Uremis I. and Uludag A., 2004. Relationships between seedbank and weed flora in cotton areas in the cukurova region of Turkey. Bull. Pure Appl. Sci. 23B, 61-69

Knezevic S.Z., Streibig J.C. and Ritz C., 2007. Utilizing R Software Package for DoseResponse Studies: The Concept and Data Analysis. Weed Technol., 21: 840-848

McMaster G.S. and Wilhelm W.W., 1997. Growing degree-days: one equation, two interpretations. Agric. Forest Meteorol., 87:291-300
Oerke E.C. and Steiner U., 1996. Absch.Tzung Der Ertragsverluste Im Maisanbau. In: Ertragsverluste Und Pflanzenschutz Die Anbausituation F.R Die Wirtschaftlich Wichtigsten Kulturpflanzen-.German Phytomedical Society Series, Band: 6, pp. 6379, Eugen Ulmer Verlag, Stuttgart

Özer Z., Kadıoğlu İ., Önen H. and Tursun N., 2001. Herboloji (Yabancı Ot Bilimi). Gaziosmanpaşa Üni. Ziraat Fak. Yay. No: 20, Kitaplar Serisi, No: 10, Tokat

Tursun N., Akinci I.E., Uludag A., Pamukoglu Z. and Gozcu D., 2012. Critical period for weed control in direct seeded red pepper (Capsicum annum L.). Weed Biology and Management.12: 109-115

Yang H.S., Dobermann A., Lindquist J.L., Walters D.T., Arkebauer T.J. and Cassman K.G., 2004. Hybrid-maize-a maize simulation model that combines two crop modeling approaches. Field Crops Res., 87: 131-154

Zimdahl R.L., 1988. The Concept and Application of the Critical Weed-Free Period. In: Weed Management in Agroecosystems: Ecological Approaches (eds MA Altieri \& M Leibman), 145- 155. CRC Press, Boca Raton, FL, USA 